\title{
Longitudinal associations between sleep disturbance and disease severity in patients with COPD
}

\author{
Faith S. Luyster ${ }^{*}$ (D), Juan Wang ${ }^{2}$, Frank C. Sciurba ${ }^{3}$ and Jessica Bon ${ }^{3,4}$
}

\begin{abstract}
Background: Sleep disturbance is a common complaint among patients with chronic obstructive pulmonary disease (COPD). Studies examining the associations between sleep disturbance and COPD severity have primarily been cross-sectional and produced conflicting results. We extended previous research by investigating the bidirectional longitudinal associations between sleep disturbance and indicators of COPD severity including airway obstruction, dyspnea, health status, exercise capacity, hyperinflation, and diffusing capacity of the lung (DLCO).

Methods: We used longitudinal data from the COPD Specialized Center for Clinically Oriented Research (SCCOR) prospective cohort. One hundred fifty-seven patients with COPD (54.1\% male, $66.3 \pm 6.4$ years) completed assessments at baseline and 2-year follow-up. Primary outcomes of interest were: sleep disturbance based on a single item from the Beck Depression Inventory; aifflow obstruction, defined by $\mathrm{FEV}_{1} \%$ predicted from spirometry; health status, as measured by the St. George's Respiratory Questionnaire; exercise capacity, as determined by walking distance (meters) during an incremental shuttle walk test; dyspnea, as measured by the modified Medical Research Council scale; DLCO, determined by single breath carbon monoxide diffusion; and hyperinflation, defined by residual volume from body plethysmography. Linear and logistic regression analyses were conducted, correcting for baseline outcome severity.
\end{abstract}

Results: After controlling for covariates of age, sex, race, body mass index, and smoking status, sleep disturbance was associated with worse health status at baseline. Using longitudinal follow-up data, greater disease severity including airflow obstruction, dyspnea, health status, exercise capacity, and DLCO independently predicted sleep disturbance at 2-year follow-up. Baseline sleep disturbance was not associated with subsequent disease severity.

Conclusions: Disease severity predicts future sleep disturbance in COPD patients. This suggests that COPD severity may be a risk factor for the development of sleep problems, and therefore better COPD control may be a preventative strategy for sleep disturbance.

Keywords: Sleep disturbance, Chronic obstructive pulmonary disease, Dyspnea, Exercise capacity

\section{Introduction}

Chronic obstructive pulmonary disease (COPD), an airway disease characterized by progressive airflow limitation that is not fully reversible, is one of the leading causes of morbidity and mortality globally (López-Campos et al. 2016). Disturbed sleep is a major complaint among patients with

\footnotetext{
* Correspondence: luysterfs@upmc.edu

${ }^{1}$ School of Nursing, University of Pittsburgh, 3500 Victoria Street, Room 415, Pittsburgh, PA 15261, USA

Full list of author information is available at the end of the article
}

COPD (Kauffman et al. 2014). Patients often report frequent nocturnal awakenings, poor sleep quality, and difficulties falling asleep (Ding et al. 2017; Omachi et al. 2012; Zeidler et al. 2018). Subjective sleep measures have been corroborated with actigraphic and polysomnographic assessments that demonstrate lower sleep efficiency and total sleep time in patients with COPD compared with controls (Nunes et al. 2013; Valipour et al. 2011).

Potential sources of sleep difficulties in COPD include smoking and psychiatric and medical comorbidities such 
as depression, anxiety, obstructive sleep apnea (OSA), restless legs syndrome (RLS), and pain (Budhiraja et al. 2015; McNicholas et al. 2013). Physiologic alterations in COPD that are accentuated during sleep including reduced airflow, ventilation/perfusion mismatch, and hypoventilation and associated hypoxemia and hypercapnia may lead to nocturnal arousals and symptoms including dyspnea, cough, and sputum production that disrupt sleep (Budhiraja et al. 2015; Kwon et al. 2009; McNicholas et al. 2013; Stephenson et al. 2015). Irrespective of the etiology, sleep disturbance has been shown to be a predictor of adverse health outcomes including COPD exacerbations and survival, thus suggesting that sleep may affect disease severity (Omachi et al. 2012; Shorofsky et al. 2019). The association between COPD severity and sleep disturbance is not clear. Indicators of disease severity including Global Initiative for Chronic Obstructive Lung Disease (GOLD) classification, airway obstruction as measured by forced expiratory volume in $1 \mathrm{~s}\left(\mathrm{FEV}_{1)}\right.$, health status, and symptoms such as cough, wheezing, dyspnea, and frequent sputum production have been found to be associated with worse sleep quality and sleep disturbance (Chang et al. 2016; Hartman et al. 2015; Nunes et al. 2013; Omachi et al. 2012; Zeidler et al. 2018). However, other studies have found no associations between airflow obstruction severity and sleep disturbance (Geiger-Brown et al. 2015; Omachi et al. 2012; Zeidler et al. 2018). In addition to the above mentioned indicators of disease severity, exercise capacity is also an important marker of disease severity. The association between sleep disturbance and exercise capacity has received little attention (VardarYagli et al. 2015; Zeidler et al. 2018).

The available literature examining the relationship between sleep disturbance and various indicators of COPD severity have reported conflicting results and have been cross-sectional, thus, it is unclear whether there may be a bi-directional relationship between sleep disturbance and disease severity in COPD. We used an established prospective longitudinal cohort of current and former smokers with COPD to examine cross-sectional and bidirectional longitudinal relationships between sleep disturbance and COPD severity. We hypothesized that (a) sleep disturbance at baseline would be associated with lower $\mathrm{FEV}_{1} \%$ predicted, increased dyspnea and hyperinflation, and reduced health status, exercise capacity, and diffusing capacity of the lung (DLCO) at baseline, (b) sleep disturbance at baseline predicts worsening FEV1\% predicted, dyspnea, health status, hyperinflation, exercise capacity, and DLCO over 2 year follow-up and (c) FEV1\% predicted, dyspnea, health status, hyperinflation, exercise capacity, and DLCO at baseline predicts the presence of sleep disturbance at 2 year follow-up in patients with COPD.

\section{Methods}

\section{Participants}

The study population consisted of participants in the single-center, COPD Specialized Center for Clinically Oriented Research (SCCOR) cohort at the University of Pittsburgh. SCCOR participants were primarily recruited from the Pittsburgh Lung Screening Study cohort, a tobacco-exposed cohort with a range of obstructive lung disease severity. The inclusion criteria for SCCOR participants were current or former smoker, age $\geq 40$ years, and a minimum 10-pack-year tobacco history at enrollment. The exclusion criteria for SCCOR participants were clinical or radiographic evidence of another pulmonary disease (e.g., interstitial lung disease), history of lung cancer or a new, suspicious nodule on CT scan, and body mass index $(\mathrm{BMI})>34$. For the current analyses, only participants who had COPD as defined by

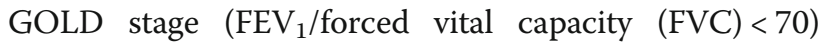
were included. A total of 426 participants from the SCCOR cohort had COPD. The present analyses were limited to those who had data available on the variables of interest at both baseline and 2 year follow-up $(N=$ 157). The group with missing data due to inability to complete assessment or missed follow-up visit had a lower proportion of current smokers and had more severe COPD as indicated by greater use of supplemental oxygen, greater oral and inhaled corticosteroid use, higher frequency of GOLD stage 4 and Group D, lower $\mathrm{FEV}_{1} \%$ predicted, exercise capacity, and DLCO, and worse dyspnea, health status, and hyperinflation than the group with data at both time points. The study was approved by the University of Pittsburgh Institutional Review Board and informed consent was obtained from all participants.

\section{Measures}

All study procedures were conducted at baseline and at 2-year follow-up. Questionnaires were administered to gather data on demographics, smoking, self-reported medical and medication history, and current use of supplemental oxygen. Participants were categorized into groups based on the 2017 GOLD "ABCD" assessment tool (Vogelmeier et al. 2017).

The Beck Depression Inventory-II (BDI-II) is a 21item measure that assesses depressive symptoms using a 4-point scale (0-3) with a maximum total score of 63 (Beck et al. 1996; Dozois et al. 1998). Depressive symptom categories include minimal (0-13), mild (14-19), moderate (20-28), and severe (29-63). A single item from the Beck Depression Inventory-II was used to assess sleep disturbance. Responses include: $0=\mathrm{I}$ can sleep as well as usual, $1=\mathrm{I}$ don't sleep as well as I used to, $2=$ I wake up 1-2 $\mathrm{h}$ earlier than I used to and find it hard to get back to sleep, $3=\mathrm{I}$ wake up several hours earlier 
than I used to and cannot get back to sleep. The variable was dichotomized into $0=$ "no disturbed sleep" and $1=$ "disturbed sleep", which encompassed responses 1-3.

The incremental shuttle walk test (ISWT) is a well validated test to assess exercise capacity in COPD patients (Singh et al. 1992; Singh et al. 1994). Participants walk on a level, ten meter course at a pace dictated by audio signals, incrementally increasing in frequency each minute, until either the participant is too breathless to maintain regular speed, is unable to complete the ten meter shuttle in the allowed time, or has walked for 20 min. Exercise capacity is defined by walking distance (meters) during the ISWT.

The modified Medical Research Council (mMRC) scale measures severity of breathlessness related to dayto-day activities on a scale from 0 (no breathlessness only with strenuous exercise) to 4 (too breathless to leave house or breathless when dressing) (Bestall et al. 1999). The St. George's Respiratory Questionnaire (SGRQ) is a 50-item measure assessing health status within three domains: symptoms, activity, and impact (Jones et al. 1991). The total score, ranges from 0 to 100, with higher scores indicating worse health status.

Pre- and post-bronchodilator spirometry was performed according to the American Thoracic Society guidelines (Miller et al. 2005). $\mathrm{FEV}_{1}$, FVC, ratio of $\mathrm{FEV}_{1}$ / FVC were recorded. Body plethysmography and single breath carbon monoxide diffusion were performed according to the recommendations of the American Thoracic Society/European Respiratory Society Task Force on standardization of lung function testing (Macintyre et al. 2005; Wanger et al. 2005).

\section{Statistical analysis}

Descriptive statistics including frequency (\%) for categorical variables and mean \pm SD for continuous variables were computed. Comparisons of variables between those with and those without sleep disturbance were performed using Student $\mathrm{t}$ test or $\mathrm{x} 2$ test. To evaluate the cross-sectional associations between sleep disturbance and indictors of COPD severity including $\mathrm{FEV}_{1} \%$ predicted (airflow obstruction), mMRC (dyspnea), SGRQ (health status), ISWT distance (exercise capacity), residual volume ((RV), hyperinflation), and DLCO, we performed linear regression analyses on the baseline data. The following covariates were included in the regression analyses: age, sex, race, BMI, and smoking status. To assess whether the presence of sleep disturbance at baseline predicted COPD severity after 2 years of follow-up, we used separate linear regression analyses. We corrected for baseline value of the respective outcome variable in the model along with the above stated covariates. To evaluate the inverse temporal relationship between these variables, we performed a logistic regression analysis with the presence of sleep disturbance $(0=$ sleep disturbance not present, 1 = sleep disturbance present) as the dependent variable, and either $\mathrm{FEV}_{1} \%$ predicted, mMRC, SGRQ, ISWT distance, residual volume, or hyperinflation at baseline as the independent variables. A two-sided $P$ value $<.05$ was set for statistical significance. All analyses were performed with SPSS 25 for Windows (IBM Corp., Armonk, NY).

\section{Results}

\section{Participant characteristics}

Table 1 presents the baseline characteristics of participants. The mean age was 66.3 years, with a roughly equal sex distribution (Table 1). The majority of participants were former smokers with mild to moderate COPD according to GOLD stage classification. Participants without sleep disturbance had higher BMI than those with sleep disturbance $(28.2 \pm 4.2$ vs. $26.9 \pm 4.0, p<0.05)$. No significant differences in the other baseline characteristics were found between those with and without disturbed sleep.

The prevalence of sleep disturbance at baseline was $47 \%$. The mean $\mathrm{FEV}_{1} \%$ predicted at baseline was $69.3 \pm 18.4$, mean mMRC $1.1 \pm 0.9$, mean SGRQ $25.0 \pm 17.2$, and ISWT distance in meters $399.6 \pm 146.71$. At follow-up, the prevalence of sleep disturbance was $53.5 \%$. The mean $\mathrm{FEV}_{1} \%$ predicted at follow-up was $68.8 \pm 18.8$, mean mMRC $1.3 \pm$ 1.1, mean SGRQ $27.6 \pm 17.4$, and ISWT distance $381.3 \pm$ $140.9 \mathrm{~m}$. Thus, the frequency of sleep disturbance increased and dyspnea, health status, and exercise capacity worsened slightly over the 2-year follow-up. Over 2-year follow-up, 8 (5.1\%) reported having an unscheduled emergency room visit and $5(3.2 \%)$ reported having a hospitalization due to an acute COPD exacerbation.

\section{Cross-sectional associations between sleep disturbance and airflow obstruction, exercise capacity, health status, dyspnea, DLCO, and hyperinflation}

At baseline, mean SGRQ was higher in participants with sleep disturbance compared to those without sleep disturbance, indicating worse health status (Table 1). In contrast, $\mathrm{FEV}_{1} \%$ predicted, dyspnea, ISWT distance, RV, and DLCO were similar in those with and without sleep disturbance. After adjustment for covariates including age, sex, race, BMI, and smoking status, the association between baseline SGRQ and presence of sleep disturbance at baseline was significance $(\beta[95 \% \mathrm{CI}]=0.22$ $[2.08,13.21], p<0.01$ ) (Table 2).

Longitudinal associations between sleep disturbance and airflow obstruction, exercise capacity, health status, dyspnea, DLCO, and hyperinflation

Baseline sleep disturbance was not associated with $\mathrm{FEV}_{1} \%$ predicted $(\beta[95 \% \mathrm{CI}]=0.03[-1.42,3.73], p=0.38)$, 
Table 1 Participant characteristics at baseline according to sleep disturbance

\begin{tabular}{|c|c|c|c|c|}
\hline & $\begin{array}{l}\text { Total } \\
(N=157)\end{array}$ & $\begin{array}{l}\text { Sleep disturbance } \\
(n=74)\end{array}$ & $\begin{array}{l}\text { No sleep disturbance } \\
(n=83)\end{array}$ & Unadjusted $p$-value \\
\hline Age, year, mean (SD) & $66.3(6.4)$ & $66.5(6.2)$ & $66.1(6.5)$ & 0.67 \\
\hline Sex, male, n (\%) & $85(54.1 \%)$ & $44(59.4 \%)$ & $41(49.4 \%)$ & 0.21 \\
\hline White, n (\%) & $151(96.2 \%)$ & 70 (94.6\%) & 81 (97.5\%) & 0.33 \\
\hline BMI, mean (SD) & $27.6(4.1)$ & $26.9(4.0)$ & $28.2(4.2)$ & 0.04 \\
\hline Pack years, mean (SD) & $64.8(34.1)$ & $66.9(34.2)$ & $62.9(34.1)$ & 0.46 \\
\hline Current smoker, n (\%) & $62(39.5 \%)$ & $35(47.3 \%)$ & $27(32.5 \%)$ & 0.06 \\
\hline Supplemental oxygen use, n (\%) & $9(5.7 \%)$ & $5(6.8 \%)$ & $4(4.8 \%)$ & 0.60 \\
\hline ICS use, n (\%) & $8(5.1 \%)$ & $6(8.1 \%)$ & $2(2.4 \%)$ & 0.11 \\
\hline OCS use, n (\%) & $40(25.5 \%)$ & $20(27.0 \%)$ & $20(24.1 \%)$ & 0.67 \\
\hline \multicolumn{5}{|l|}{ GOLD stage, n (\%) } \\
\hline Stage 1 & $46(29.3 \%)$ & $20(27.0 \%)$ & $26(31.3 \%)$ & \multirow[t]{4}{*}{0.77} \\
\hline Stage 2 & $87(55.4 \%)$ & $42(63.5 \%)$ & $45(54.2 \%)$ & \\
\hline Stage 3 & $21(13.4 \%)$ & $10(13.5 \%)$ & $11(13.3 \%)$ & \\
\hline Stage 4 & $3(1.9 \%)$ & $2(2.7 \%)$ & $1(1.2 \%)$ & \\
\hline \multicolumn{5}{|l|}{ GOLD ABCD group, n (\%) } \\
\hline Group A & $106(67.5 \%)$ & $47(63.5 \%)$ & $59(71.1 \% 0$ & \multirow[t]{4}{*}{0.64} \\
\hline Group B & $26(16.6 \%)$ & $13(17.6 \%)$ & $13(15.7 \% 0$ & \\
\hline Group C & $14(8.9 \%)$ & 7 (9.5\%) & 7 (8.4\%) & \\
\hline Group D & $11(7.0 \%)$ & 7 (9.5\%) & $4(4.8 \%)$ & \\
\hline \multicolumn{5}{|l|}{ Comorbidities, n (\%) } \\
\hline Diabetes & $9(5.7 \%)$ & $3(4.2 \%)$ & $6(7.2 \%)$ & 0.42 \\
\hline Hyperlipidemia & $84(53.5 \%)$ & 39 (53.4\%) & $45(55.6 \%)$ & 0.79 \\
\hline Cancer & $25(15.9 \%)$ & $8(10.8 \%)$ & 17 (20.5\%) & 0.10 \\
\hline Asthma & $17(10.8 \%)$ & $30(40.5 \%)$ & $20(24.7 \%)$ & 0.32 \\
\hline GERD & $50(31.8 \%)$ & $10(13.9 \%)$ & $7(8.8 \%)$ & 0.04 \\
\hline Bronchitis & $75(47.8 \%)$ & $42(60.0 \%)$ & $33(42.3 \%)$ & 0.03 \\
\hline \multicolumn{5}{|l|}{ BDI-II category, n (\%) } \\
\hline Minimal/Mild & $151(96.2 \%)$ & 69 (93.2\%) & $82(98.8 \%)$ & 0.07 \\
\hline Moderate/ Severe & $6(3.8 \%)$ & $5(6.8 \%)$ & $1(1.2 \%)$ & 0.56 \\
\hline $\mathrm{FEV}_{1}$ pp., mean (SD) & $69.3(18.4)$ & $8.4(19.0)$ & $70.2(18.1)$ & 0.40 \\
\hline mMRC, mean (SD) & $1.1(0.9)$ & $1.1(1.1)$ & $0.9(0.9)$ & 0.005 \\
\hline SGRQ, mean (SD) & $25.0(17.2)$ & $29.0(18.1)$ & $21.4(15.6)$ & 0.72 \\
\hline ISWT distance (m), mean (SD) & $399.6(146.7)$ & $394.9(141.8)$ & $403.6(152.0)$ & 0.58 \\
\hline RV pp., mean (SD) & $138.4(35.9)$ & $140.1(34.8)$ & $136.8(37.0)$ & 0.99 \\
\hline $\mathrm{RV} / \mathrm{TLC}$, mean (SD) & $0.49(0.10)$ & $0.49(0.10)$ & $0.49(0.10)$ & 0.15 \\
\hline DLCO pp., mean (SD) & $66.9(19.8)$ & $64.5(21.6)$ & $69.1(18.0)$ & 0.56 \\
\hline
\end{tabular}

$B D I-I I$ Beck Depression Inventory-II, $B M I$ body mass index, $F E V_{1} p p$ forced expiratory volume in $1 \mathrm{~s}$ percent predicted, GERD gastroesophageal reflux disease, $S D$ standard deviation, $m M R C$ modified Medical Research Council scale, SGRQ St. George's Respiratory Questionnaire, ISWT = Incremental shuttle walk test, $R V p p$ residual capacity percent predicted, DLCO pp diffusion capacity for carbon monoxide percent predicted

${ }^{a}$ Oral steroid use, temporary short-term use in past 6 months

$\operatorname{mMRC}(\beta[95 \% \mathrm{CI}]=0.11[-0.05,0.55], p=0.10), \mathrm{SGRQ}$ $(\beta[95 \% \mathrm{CI}]=0.01[-2.68,3.51], p=0.79)$, ISWT distance $(\beta[95 \% \mathrm{CI}]=-0.02[-31.63,23.28], p=0.76), \mathrm{RV}(\beta[95 \%$ $\mathrm{CI}]=0.03[-5.08,9.62], p=0.54)$, or DLCO $(\beta[95 \% \mathrm{CI}]=$ -0.06 [-5.32, 0.37], $p=0.09$ ) at 2-year follow-up, after correcting the model for baseline values of these independent variables and covariates including age, sex, race, BMI, and smoking status (Table 3). When looking at the reverse relationships, baseline mMRC $(\mathrm{OR}[95 \% \mathrm{CI}]=1.77$ $[1.16,2.68, \mathrm{p}=<0.01)$, SGRQ (OR $[95 \% \mathrm{CI}]=1.04[1.01$, 


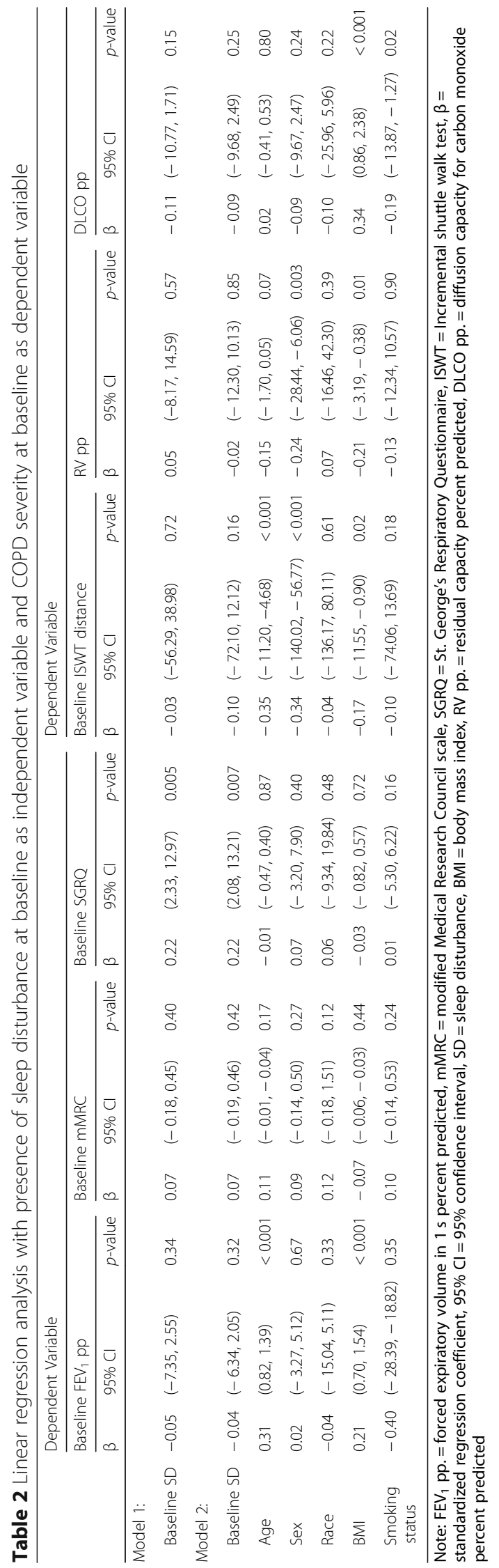




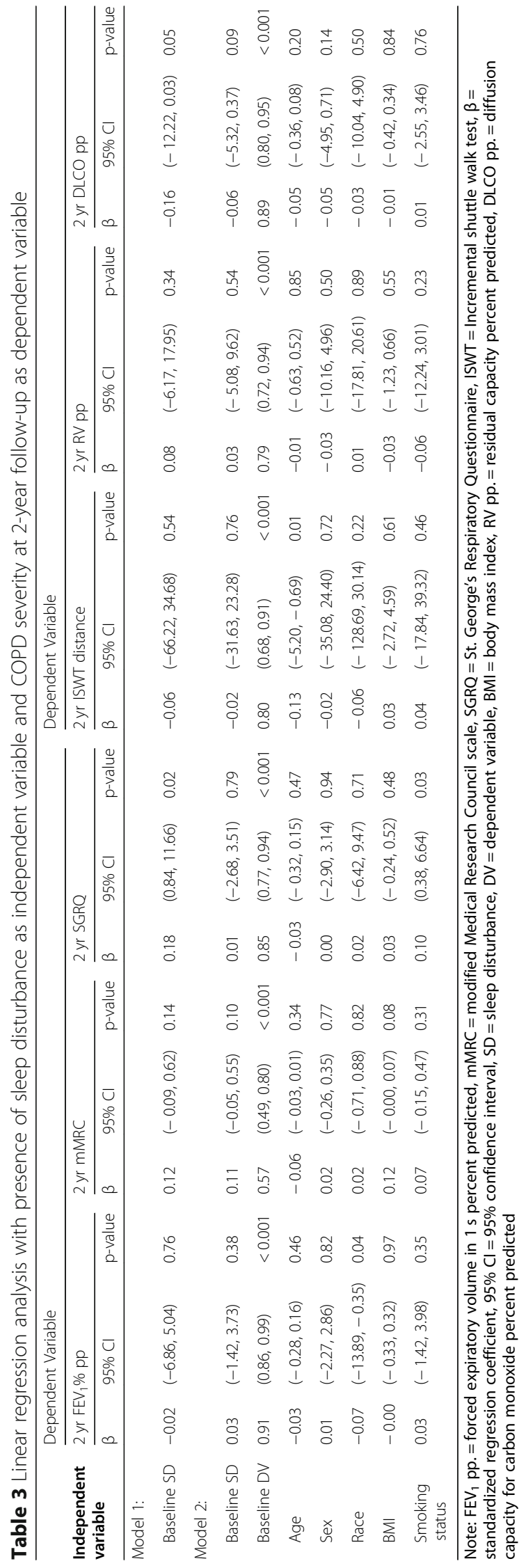


1.06], $\mathrm{p}=<0.01)$, ISWT distance (OR $[95 \% \mathrm{CI}]=0.99$ $[0.99,1.00], \mathrm{p}=<0.05)$, and DLCO (OR $[95 \% \mathrm{CI}]=0.98$ $[0.96,0.99], p=0.03)$ were significantly associated with the presence of sleep disturbance at 2 years follow-up (Table 4). The association between baseline $\mathrm{FEV}_{1} \%$ predicted and presence of sleep disturbance at follow-up approached significance $(\mathrm{OR}[95 \% \mathrm{CI}]=0.98[0.96,1.00]$, $p=0.05)$. RV at baseline was not significantly associated with presence of sleep disturbance at follow-up.

\section{Discussion}

In this study, we examined the cross-sectional and bidirectional longitudinal relationships between sleep disturbance and indicators of disease severity in a cohort of current and former smokers with COPD. Crosssectional analyses revealed a significant association between sleep disturbance and health status but no significant associations between sleep disturbance and airflow obstruction, dyspnea, exercise capacity, hyperinflation, or DLCO. Baseline sleep disturbance was not a predictor of the disease severity indictors at 2-year follow-up, whereas airflow obstruction, dyspnea, health status, exercise capacity, and DLCO at baseline were predictors of sleep disturbance at follow-up.

A significant relationship between sleep disturbance and health status at baseline was found, yet the other indicators of COPD severity were not associated with sleep disturbance. These findings are in broad agreement with prior cross-sectional studies, which have demonstrated associations between sleep quality and health status (Lee et al. 2019; Scharf et al. 2011; Zeidler et al. 2018), but no associations with airflow obstruction or exercise capacity (Geiger-Brown et al. 2015; Omachi et al. 2012; VardarYagli et al. 2015; Zeidler et al. 2018). However, an association between lower sleep efficiency and increased severity of hyperinflation was reported in a sample of

Table 4 Logistic regression analyses with COPD severity at baseline as independent variable and sleep disturbance at 2year follow-up as dependent variable

\begin{tabular}{lll}
\hline & OR $(95 \% \mathrm{Cl})$ & p-value \\
\hline FEV 1 pp & $0.98(0.96,1.00)$ & 0.05 \\
mMRC & $1.77(1.16,2.68)$ & 0.008 \\
SGRQ & $1.04(1.01,1.06)$ & 0.004 \\
ISWT distance & $0.99(0.99,1.00)$ & 0.04 \\
RV pp & $1.01(0.99,1.02)$ & 0.38 \\
DLCO pp & $0.98(0.96,0.99)$ & 0.03 \\
\hline
\end{tabular}

Note: All analyses control for age sex, race, body mass index, and smoking. Each COPD severity variable above was used as an independent variable in its own multivariable logistic regression analysis. $\mathrm{FEV}_{1}$ pp.forced expiratory volume in $1 \mathrm{~s}$ percent predicted, $m M R C$ modified Medical Research Council scale, SGRQ St. George's Respiratory Questionnaire, ISWT Incremental shuttle walk test, OR odds ratio, $95 \% \mathrm{Cl} 95 \%$ confidence interval, $R V \mathrm{pp}$. residual capacity percent predicted, DLCO $p p$. diffusion capacity for carbon monoxide percent predicted patients with COPD and obstructive sleep apnea (Kwon et al. 2009). Our findings suggest that that sleep disturbance may be more strongly linked to health status than these other markers of disease severity.

We found that sleep disturbance did not predict dyspnea, health status, airflow obstruction, exercise capacity, hyperinflation, or DLCO at follow-up after correction for baseline outcome severity. This is in contrast to prior studies in which poor sleep independently predicted subsequent exacerbations up to 18 months later suggesting that sleep disturbance is a risk factor for poor outcomes in COPD (Omachi et al. 2012; Shorofsky et al. 2019). There are several potential mechanisms by which sleep disturbance could contribute to worsening COPD. Poor sleep may affect immune function thus increasing susceptibility to infections (Majde and Krueger 2005; Veeramachaneni and Sethi 2006), accentuate systematic inflammation (Dumaine and Ashley 2015; MacNee 2013), lead to impaired cognitive function and resultant medication nonadherence (Fortier-Brochu et al. 2012; Riegel and Weaver 2009), and could be a manifestation of untreated OSA (Marin et al. 2010), all of which can worsen COPD control. The lack of association between sleep disturbance and disease severity in the current study could be explained by the measure used to assess sleep disturbance. We used a single item from the BDI. Previous studies examining associations between sleep and COPD outcomes have primarily used validated sleep instruments (e.g., Pittsburgh Sleep Quality Index), therefore use of validated subjective and objective measures of sleep may have yielded differing results. Furthermore, our cohort mostly had mild to moderate COPD with infrequent exacerbations, thus association may have been found in a cohort with a higher rate of acute exacerbations.

We found that baseline dyspnea, health status, airflow obstruction, exercise capacity, and DLCO predicted occurrence of sleep disturbance at 2 year follow-up. Reduced airflow could affect sleep due to nocturnal arousals associated with hypoxemia and hypercapnia caused by accentuated hypoventilation, particularly during rapid eye movement (REM) sleep (Budhiraja et al. 2015). Hypoxemia in individuals with marked diffusion limitation may contribute to nocturnal dyspnea which can be particularly disruptive to sleep. Reduced exercise capacity may be a marker of lung disease severity, but may also be reflective of comorbidities such as cardiovascular disease or obstructive sleep apnea, which can lead to sleep disturbance (Lavie et al. 2015; Mendelson et al. 2018). Depression and anxiety associated with dyspnea and reduced exercise capacity could also lead to sleep disturbance (Al-shair et al. 2009; Chavannes et al. 2005; Kim et al. 2014; Shackell et al. 2007; Suh et al. 2013).

Findings from this study should be interpreted in consideration of certain limitations. As previously stated, 
sleep disturbance was not assessed by a validated sleep questionnaire. Furthermore, objective assessment of sleep such as polysomnography was not conducted, thus prohibiting us from understanding the etiology of the sleep disturbance which could have in part been related to sleep disordered breathing. We excluded individuals with missing data at follow-up who were those with more severe COPD, which limits generalizability of the results to those with greater disease severity.

\section{Conclusions}

We found airflow obstruction, dyspnea, health status, exercise capacity, and DLCO predict future sleep disturbance in individuals with COPD. Future research should utilize validated sleep assessments to further our understanding of the directionality of the relationship between sleep disturbance and COPD severity. This study suggests that COPD severity may be a risk factor for the development of sleep problems, and therefore better COPD control may be a preventative strategy for sleep disturbance.

\section{Abbreviations \\ BDI-II: Beck Depression Inventory-II; BMI: Body Mass Index; COPD: Chronic Obstructive Pulmonary Disease; DLCO: Diffusing Capacity of the Lung; $F_{1}$ : Forced Expiratory Volume in One Second; FVC: Forced Vital Capacity; GERD: Gastroesophageal Reflux Disease; GOLD: Global Initiative for Chronic Obstructive Lung Disease; ISWT: Incremental Shuttle Walk Test; mMRC: Modified Medical Research Council scale; REM: Rapid Eye Movement; RV: Residual Volume; SCCOR: Specialized Center For Clinically Oriented Research; SGRQ: St. George's Respiratory Questionnaire}

\section{Acknowledgements}

Not applicable.

\section{Authors' contributions}

FSL conceptualized the idea for the manuscript, analyzed and interpreted the data as well as wrote the manuscript. JW played a role in the interpretation of results and manuscript editing and revision. FCS had a role in the study design, data collection, interpretation of results, and manuscript revision. JB had a role in the study design, data collection, interpretation of results and manuscript editing and revision. All authors read and approved the final manuscript.

\section{Funding}

This study was supported by the National Institutes of Health grants P50 HL084948, P50 CA90440, P30 AG024827, and R01 HL128289.

\section{Availability of data and materials}

The raw data on which results in the current study are based may be requested from the corresponding author upon reasonable request.

\section{Ethics approval and consent to participate}

The study was approved by the Institutional Review Board at the University of Pittsburgh prior to study initiation. Informed consent to participate was obtained from each participant prior to study enrollment.

\section{Consent for publication}

Not applicable.

\section{Competing interests}

The authors declare that they have no competing interests.

\section{Author details}

${ }^{1}$ School of Nursing, University of Pittsburgh, 3500 Victoria Street, Room 415, Pittsburgh, PA 15261, USA. ${ }^{2}$ Respiratory Department of Tianjin, Medical University General Hospital, Tianjin 300052, China. ${ }^{3}$ Division of Pulmonary, Allergy and Critical Care Medicine, Department of Medicine, University of Pittsburgh, Pittsburgh, PA, USA. ${ }^{4}$ VA Pittsburgh Healthcare System, Pittsburgh, PA, USA.

Received: 29 January 2020 Accepted: 20 May 2020

Published online: 02 July 2020

\section{References}

Al-shair K, Dockry R, Mallia-Milanes B, Kolsum U, Singh D, Vestbo J. Depression and its relationship with poor exercise capacity, BODE index and muscle wasting in COPD. Respir Med. 2009;103(10):1572-9.

Beck AT, Steer RA, Brown GK. Beck depression inventory-II. San Antonio, TX: Psychological Corporation; 1996.

Bestall JC, Paul EA, Garrod R, Garnham R, Jones PW, Wedzicha JA. Usefulness of the Medical Research Council (MRC) dyspnoea scale as a measure of disability in patients with chronic obstructive pulmonary disease. Thorax. 1999;54:581-6.

Budhiraja R, Siddiqi TA, Quan SF. Sleep disorders in chronic obstructive pulmonary disease: etiology, impact, and management. J Clin Sleep Medi. 2015;11(03):259-70.

Chang C-H, Chuang L-P, Lin S-W, Lee C-S, Tsai Y-H, Wei Y-F, et al. Factors responsible for poor sleep quality in patients with chronic obstructive pulmonary disease. BMC Pulm Med. 2016;16(1):118.

Chavannes N, Huibers M, Schermer T, Hendriks A, Van Weel WEF, et al. Associations of depressive symptoms with gender, body mass index and dyspnea in primary care COPD patients. Fam Pract. 2005;22(6):604-7.

Ding B, Small M, Bergström G, Holmgren U. A cross-sectional survey of nighttime symptoms and impact of sleep disturbance on symptoms and health status in patients with COPD. Int J Chron Obstruct Pulmon Dis. 2017;12:589.

Dozois DJ, Dobson KS, Ahnberg JL. A psychometric evaluation of the Beck Depression Inventory-II. Psychol Assessment. 1998;10(2):83-9.

Dumaine JE, Ashley NT. Acute sleep fragmentation induces tissue-specific changes in cytokine gene expression and increases serum corticosterone concentration. Am J Physiol Regul Integr Comp Physiol. 2015;308(12):R1062-9.

Fortier-Brochu É, Beaulieu-Bonneau S, Ivers H, Morin CM. Insomnia and daytime cognitive performance: a meta-analysis. Sleep Med Rev. 2012;16(1):83-94.

Geiger-Brown J, Lindberg S, Krachman S, McEvoy CE, Criner GJ, Connett JE, et al. Self-reported sleep quality and acute exacerbations of chronic obstructive pulmonary disease. Int J Chron Obstruct Pulmon Dis. 2015;10:389-97.

Hartman J, Prinzen J, van Lummel R, ten Hacken N. Frequent sputum production is associated with disturbed night's rest and impaired sleep quality in patients with COPD. Sleep Breath. 2015;19(4):1125-33.

Jones PW, Quirk F, Baveystock CM. The St George's respiratory questionnaire. Resp med. 1991;85:25-31.

Kauffman KS, Doede M, Diaz-Abad M, Scharf SM, bell-Farrell W, Rogers VE, et al. Experience of insomnia, symptom attribution and treatment preferences in individuals with moderate to severe COPD: a qualitative study. Patient Pref Adherence. 2014;8:1699-704.

Kim KU, Park H-K, Jung HY, Ahn JJ, Moon E, Kim YS, et al. Association of depression with disease severity in patients with chronic obstructive pulmonary disease. Lung. 2014;192(2):243-9.

Kwon JS, Wolfe LF, Lu BS, Kalhan R. Hyperinflation is associated with lower sleep efficiency in COPD with co-existent obstructive sleep apnea. COPD. 2009;6(6): $441-5$

Lavie CJ, Arena R, Swift DL, Johannsen NM, Sui X, Lee D-C, et al. Exercise and the cardiovascular system: clinical science and cardiovascular outcomes. Circ Res. 2015;117(2):207-19.

Lee SH, Kim KU, Lee H, Park H-K, Kim YS, Lee MK. Sleep disturbance in patients with mild-moderate chronic obstructive pulmonary disease. Clin Respir J. 2019;00:1-7.

López-Campos JL, Tan W, Soriano JB. Global burden of COPD. Respirology. 2016; 21(1):14-23.

Macintyre N, Crapo RO, Viegi G, Johnson DC, van der Grinten CP, Brusasco V, et al. Standardisation of the single-breath determination of carbon monoxide uptake in the lung. Eur Respir J. 2005;26(4):720-35.

MacNee W. Systemic inflammatory biomarkers and co-morbidities of chronic obstructive pulmonary disease. Ann Med. 2013;45(3):291-300. 
Majde JA, Krueger JM. Links between the innate immune system and sleep. J Allergy Clin Immunol. 2005;116(6):1188-98.

Marin JM, Soriano JB, Carrizo SJ, Boldova A, Celli BR. Outcomes in patients with chronic obstructive pulmonary disease and obstructive sleep apnea: the overlap syndrome. Am J Respir Crit Care Med. 2010;182(3):325-31.

McNicholas WT, Verbraecken J, Marin JM. Sleep disorders in COPD: the forgotten dimension. Eur Respir Rev. 2013;22(129):365-75.

Mendelson M, Marillier M, Bailly S, Flore P, Borel JC, Vivodtzev, et al. Maximal exercise capacity in patients with obstructive sleep apnoea syndrome: a systematic review and meta-analysis. Eur Respir J. 2018;51(6):1702697.

Miller MR, Hankinson J, Brusasco V, et al. Standardisation of spirometry. Eur Respir J. 2005;26(2):319-38.

Nunes DM, de Bruin VM, Louzada FM, Peixoto CA, Cavalcante AG, Castro-Silva C, et al. Actigraphic assessment of sleep in chronic obstructive pulmonary disease. Sleep Breath. 2013;17(1):125-32.

Omachi TA, Blanc PD, Claman DM, Chen H, Yelin EH, Julian L, et al. Disturbed sleep among COPD patients is longitudinally associated with mortality and adverse COPD outcomes. Sleep Med. 2012;13(5):476-83.

Riegel B, Weaver TE. Poor sleep and impaired self-care: towards a comprehensive model linking sleep, cognition, and heart failure outcomes. Eur J Cardiovasc Nur. 2009;8(5):337-44.

Scharf SM, Maimon N, Simon-Tuval T, Bernhard-Scharf B, Reuveni H, Tarasiuk A. Sleep quality predicts quality of life in chronic obstructive pulmonary disease. Int J Chron Obstruct Pulmon Dis. 2011;6:1-12.

Shackell BS, Jones RC, Harding G, Pearse S, Campbell J. Am I going to see the next morning?'a qualitative study of patients' perspectives of sleep in COPD. Prim Care Respir J. 2007;16(6):378.

Shorofsky M, Bourbeau J, Kimoff J, Jen R, Malhotra A, Ayas N, et al. Impaired sleep quality in COPD is associated with exacerbations: the CanCOLD cohort study. Chest. 2019 May 28. https://doi.org/10.1016/j.chest.2019.04.132 [Epub ahead of print].

Singh S, Morgan M, Hardman A, Rowe C, Bardsley PA. Comparison of oxygen uptake during a conventional treadmill test and the shuttle walking test in chronic airflow limitation. Eur Respir J. 1994;7(11):2016-20.

Singh SJ, Morgan M, Scott S, Walters D, Hardman AE. Development of a shuttle walking test of disability in patients with chronic airways obstruction. Eur Respir J. 1992:47(12):1019-24.

Stephenson JJ, Cai Q, Mocarski M, Tan H, Doshi JA, Sullivan SD. Impact and factors associated with nighttime and early morning symptoms among patients with chronic obstructive pulmonary disease. Int J Chron Obstruct Pulmon Dis. 2015;10:577-86.

Suh S, Ellis RJ, Sollers JJ III, Thayer JF, Yang H-C, Emery CF. The effect of anxiety on heart rate variability, depression, and sleep in chronic obstructive pulmonary disease. J Psychosom Res. 2013;74(5):407-13.

Valipour A, Lavie P, Lothaller H, Mikulic I, Burghuber OC. Sleep profile and symptoms of sleep disorders in patients with stable mild to moderate chronic obstructive pulmonary disease. Sleep Med. 2011;12(4):367-72.

Vardar-Yagli N, Saglam M, Savci S, Inal-Ince D, Calik-Kutukcu E, Arikan H, et al. Impact of sleep quality on functional capacity, peripheral muscle strength and quality of life in patients with chronic obstructive pulmonary disease. Expert Rev Respir Med. 2015;9(2):233-9.

Veeramachaneni SB, Sethi S. Pathogenesis of bacterial exacerbations of COPD. COPD. 2006;3(2):109-15

Vogelmeier CF, Criner GJ, Martinez FJ, Anzueto A, Barnes PJ, Bourbeau J, et al. Global strategy for the diagnosis, management, and prevention of chronic obstructive lung disease 2017 report. GOLD executive summary. Am J Respir Crit Care Med. 2017;195(5):557-82.

Wanger J, Clausen JL, Coates A, Pedersen OF, Brusasco V, Burgos F, Casaburi R, et al. Standardisation of the measurement of lung volumes. Eur Respir J. 2005;26(3):511-22.

Zeidler MR, Martin JL, Kleerup EC, Schneider H, Mitchell MN, Hansel NN, et al. Sleep disruption as a predictor of quality of life among patients in the subpopulations and intermediate outcome measures in COPD study (SPIROMICS). Sleep. 2018;41(5). https://doi.org/10.1093/sleep/zsy044

\section{Publisher's Note}

Springer Nature remains neutral with regard to jurisdictional claims in published maps and institutional affiliations.

Ready to submit your research? Choose BMC and benefit from:

- fast, convenient online submission

- thorough peer review by experienced researchers in your field

- rapid publication on acceptance

- support for research data, including large and complex data types

- gold Open Access which fosters wider collaboration and increased citations

- maximum visibility for your research: over $100 \mathrm{M}$ website views per year

At $\mathrm{BMC}$, research is always in progress.

Learn more biomedcentral.com/submissions 